University of Wollongong

Research Online

SMART Infrastructure Facility - Papers

Faculty of Engineering and Information

Sciences

$1-1-2015$

\title{
A utility-driven approach to supplier evaluation and selection: empirical validation of an integrated solution framework
}

\author{
Alptekin Ulutas \\ University of Wollongong, au683@uowmail.edu.au \\ Nagesh Shukla \\ University of Wollongong, nshukla@uow.edu.au \\ Senevi Kiridena \\ University of Wollongong, skiriden@uow.edu.au \\ Peter Gibson \\ University of Wollongong, peterg@uow.edu.au
}

Follow this and additional works at: https://ro.uow.edu.au/smartpapers

Part of the Engineering Commons, and the Physical Sciences and Mathematics Commons 


\title{
A utility-driven approach to supplier evaluation and selection: empirical validation of an integrated solution framework
}

\begin{abstract}
Supplier evaluation and selection (SES) problems have long been studied, leading to the development of a wide range of individual and hybrid models for solving them. However, the lack of widespread diffusion of existing SES models in the industry points to a need for simpler models that can systematically evaluate both qualitative and quantitative attributes of potential suppliers while enhancing the flexibility decisionmakers need to account for relevant situational factors. Furthermore, empirical validations of existing models in SES have been few and far between. With a view to addressing these issues, this paper proposes an integrated solution framework that can be used to evaluate both tangible and intangible attributes of potential suppliers. The proposed framework combines three individual methods, namely the fuzzy analytic hierarchy process, fuzzy complex proportional assessment and fuzzy linear programming. The framework is validated through application in a Turkish textile company. The results generated using the proposed framework is compared with the actual historical data collected from the company.

Additionally, a feasibility assessment is conducted on the sample supplier selection criteria employed, as well as assessment of the results generated using the proposed model.
\end{abstract}

\section{Keywords}

approach, integrated, driven, validation, utility, solution, empirical, framework, selection, evaluation, supplier

\section{Disciplines}

Engineering | Physical Sciences and Mathematics

\section{Publication Details}

Ulutas, A., Shukla, N., Kiridena, S. \& Gibson, P. (2015). A utility-driven approach to supplier evaluation and selection: empirical validation of an integrated solution framework. International Journal of Production Research, 54 (5), 1554-1567. 


\title{
A Utility-driven Approach to Supplier Evaluation and Selection: Empirical Validation of an Integrated Solution Framework
}

\author{
Alptekin Ulutas $^{1}$, Nagesh Shukla ${ }^{2}$, Senevi Kiridena ${ }^{1}$, Peter Gibson ${ }^{1}$ \\ ${ }^{1}$ School of Mechanical, Materials \& Mechatronic Engineering, University of Wollongong, \\ Wollongong 2522, NSW, Australia \\ ${ }^{2}$ SMART Infrastructure Facility, University of Wollongong, Wollongong 2522, NSW,
} Australia

\begin{abstract}
Supplier evaluation and selection (SES) problems have long been studied, leading to the development of a wide range of individual and hybrid models for solving them. However, the lack of widespread diffusion of existing SES models in the industry points to a need for simpler models that can systematically evaluate both qualitative and quantitative attributes of potential suppliers while enhancing the flexibility decision-makers need to account for relevant situational factors. Furthermore, empirical validations of existing models in SES have been few and far between. With a view to addressing these issues, this paper proposes an integrated solution framework that can be used to evaluate both tangible and intangible attributes of potential suppliers. The proposed framework combines three individual methods, namely the Fuzzy Analytic Hierarchy Process (FAHP), Fuzzy Complex Proportional Assessment (COPRAS-F) and Fuzzy Linear Programming (FLP). The framework is validated through application in a Turkish textile company. The results generated using the proposed framework is compared with the actual historical data collected from the company. Additionally, a feasibility assessment is conducted on the sample supplier selection criteria employed, as well as an assessment of the results generated using the proposed model.
\end{abstract}

Key words: Supplier Evaluation and Selection, Fuzzy Analytic Hierarchy Process, Fuzzy Complex Proportional Assessment, Fuzzy Linear Programming.

\section{INTRODUCTION}

The SES literature often emphasises the importance of being able to carefully select potential suppliers, particularly in light of current trends such as increased levels of outsourcing, global sourcing and the need for maintaining closer and longer-term relationships with a small number of competent suppliers (Setak, Sharifi and Alimohammadian 2012; Agarwal et al., 2011; Jain, Wadhwa and Deshmukh 2009). Major reviews of SES literature suggest that the key focus of recent research has been on dealing with the increasing diversity and complexity of decision-making contexts, with each new model proposed striving to demonstrate its effectiveness in terms of the evaluation criteria and techniques used (Jain, Wadhwa and Deshmukh 2009; Sonmez 2006; De Boer, Labro and Morlacchi 2001). Recently, there has 
been a heightened emphasis on accounting for the criteria that represent the environmental and sustainability aspects of supplier performance (Zhang et al., 2014; Igarashi, De Boer and Fet 2013).

The major limitations of current SES research, as reported in the literature, include: a lack of methods supporting the early stages of the SES process; a lack of methods particularly suitable for service and public sector applications; and a lack of attention to emerging perspectives such as buyer-supplier relationships, design collaboration, e-procurement and supply chain security in the SES process (Jain, Wadhwa and Deshmukh 2009; Aissaoui, Haouari and Hassini 2007; Sonmez 2006). There is also a strong call for more comprehensive models and techniques which systematically combine the qualitative and quantitative attributes of the SES problem and which enhance the flexibility decision-makers need to account for relevant situational factors (Jain, Wadhwa and Deshmukh 2009; Sonmez 2006).

While acknowledging the challenges associated with addressing the full spectrum of the abovementioned limitations in a single study, this paper presents an integrated SES framework which has been developed to address the latter point. To this end, in selecting individual techniques, we have paid particular attention to the nature and limitations of the information available for decision-making. Furthermore, we contend that the proposed framework has a degree of built-in flexibility with respect to the objectives and criteria used so it can be adapted to suit varying contexts without substantially compromising its efficacy.

The paper is structured as follows. In the next section, we provide a summary review of the relevant literature. This review highlights the key issues and challenges, as well as recent trends, pertaining to solving SES problems. It then articulates the limitations of existing SES models and techniques. Considering these perspectives, and following a brief account of the methodological approach used, we introduce the proposed integrated SES framework. Application of the proposed framework is then demonstrated through an empirical case study drawn from the Turkish textile industry. The results of the case study are then discussed in the context of extant literature. The paper concludes with a brief account of the limitations of the proposed model, its implications for theory, as well as practice, and directions for further research.

\section{LITERATURE REVIEW}

For the purposes of this paper, an SES problem is defined as the identification, evaluation and assigning of appropriate suppliers capable of fulfilling orders (for the supply of materials, 
components, products and services) placed by the buyer organisation according to an agreed set of objectives, terms and conditions (Aissaoui, Haouari and Hassini 2007; Benyoucef, Ding and Xie 2003). The inclusion of order allocation in the SES process means that it is intrinsically considered to be a multiple-sourcing environment.

Research has identified a number of factors that influence SES decisions - for example, decision-making context, manufacturing and sourcing strategies, the type of product and supplier capacity. Depending on the relevance and the extent of influence of these factors, variations to the SES process described above are expected in certain situations. Based on our review of the SES literature, we identify the following aspects as having consistently attracted widespread attention from researchers: purchasing context, decision-making context, the nature and availability of information on supplier capability and performance, uncertainty and buyer-supplier relationships. Anecdotal, as well as limited empirical evidence suggests that, despite the complexities involved, SES decisions in many organisations are often made based on the intuitive judgement of senior managers, facilitated by simple weighting techniques (Koul and Verma 2011; Viana and Alencar 2011). Although there have been several publications examining the usefulness of systematic and comprehensive methods for evaluating and selecting suppliers, the growing array of models proposed in the literature has rarely been subject to empirical validation (Sonmez 2006; De Boer and Van der Wegen 2003; Choi and Hartley 1996). We believe this lack of diffusion of SES models in the industry is partly due to the proliferation of models and techniques that have not been subject to empirical validation.

The major classes of SES techniques cited in the literature include: linear weighting techniques, mathematical programing models, statistical models, total cost of ownership models and artificial intelligence techniques (Aissaoui, Haouari and Hassini 2007; De Boer, Labro and Morlacchi 2001). Specific techniques within each category possess inherent strengths and limitations in terms of addressing certain facets of the SES problem and their capacity to deal with the situational factors identified earlier. These strengths and limitations have been extensively dealt with in the major reviews of the SES literature, cited earlier in this paper, as well as in several other publications where integrated models have been proposed.

In addition to the advantage of their obvious simplicity, linear weighting models are capable of accommodating both tangible and intangible attributes and handling imprecise data, though at the expense of objectivity and hence the accuracy of final outcomes. Successive contributions in this area have resulted in a suite of more advanced techniques 
capable of accounting for the uncertainty and imprecision associated with SES decisionmaking. These advanced techniques include analytic hierarchy or analytical network processes (AHP, ANP), data envelopment analysis (DEA), the technique for the order performance by similarity to ideal solution (TOPSIS), multi-attribute utility theory (MAUT), fuzzy sets theory (FST) and outranking methods.

The family of mathematical programming (MP) models used for solving the SES problem include classical linear programing (LP) models, as well as other forms such as integer or mixed integer programming (IP, MIP), multi-objective LP (MOLP) and goal programming (GP). Although MP techniques are precise, the fact that they can only consider tangible attributes or quantitative data acts as a major limitation. To address this issue, as well as the issue of uncertainty, MP techniques have been combined with other techniques such as data envelopment analysis (DEA) and AHP or ANP.

Statistical models, by comparison, are particularly suitable for dealing with the uncertainties surrounding SES problems, such as random variations in demand or lead time. Although they are suitable for solving SES problems more comprehensively at an aggregate level, some inherent limitations can act as impediments to generating accurate and tangible solutions. The reliability of the results is directly associated with the size of the data samples used. Lack of historical data may also act as a barrier to effective application of these models.

The other two types of techniques used in SES are total cost of ownership (TCO) models and artificial intelligence (AI) approaches. Although TCO models are popular within the area of management accounting, the difficulties associated with quantifying all costs can be a significant problem, especially when dealing with a variety of items with low unit costs as opposed to a smaller number of capital intensive items. The family of AI approaches (Dashora et al. 2008; Shukla et al. 2009; Shukla et al. 2015) consists of methods such as expert systems, case-based reasoning and neural networks, which do not require mathematical formalisation of the decision problem. These techniques can formulate and solve new problems based on previous scenarios or expert knowledge. As such, they are considered to be capable of better dealing with the complexity and ambiguity associated with SES problems. However, given the abstract nature of the computer-based algorithms employed, interpretation of the decision logic followed by AI techniques can be problematic for decision-makers. AI methods also require the setting up of a range of algorithmic parameters which further restricts their use in practice.

Recent research efforts have largely focused on addressing the trade-offs referred to above by combining carefully selected individual techniques into hybrid or integrated 
models. These hybrid models have been found to be quite effective in terms of addressing the limitations of the individual techniques discussed above, but have not been widely diffused into industry. A major reason for this slow diffusion is their lack of appeal to practitioners. The most advanced and sophisticated hybrid models may demand: professionals trained in their selection and application; the access to and organisation of data in appropriate formats; and a good deal of knowledge and understanding of the context in which they are to be used. As such, there is still a need for simpler yet efficient and effective models which systematically account for both the tangible and the intangible attributes of the SES problem and which enhance the flexibility decision-makers need to account for relevant situational factors (Jain, Wadhwa and Deshmukh 2009; Sonmez 2006).

\section{PROPOSED SOLUTION FRAMEWORK AND METHODOLOGY}

In recognition of the limitations of the existing models and other broader issues identified in the literature, this paper presents an integrated SES framework developed to address both the tangible and intangible attributes of SES problems. The individual techniques that make up the integrated framework were selected considering: the nature of information available for decision-making; variability associated with the measurement of performance; and the need to allow for a degree of flexibility with respect to the objectives and criteria used, so the framework can be adapted to suit varying contexts. The overall design is aimed at maximising the utility of the proposed framework in terms of both its appeal to practitioners and its analytical rigour.

\subsection{Overview of the Integrated Framework}

The proposed framework, illustrated in Figure 1, can be used to evaluate potential suppliers in terms of both tangible and intangible attributes either sequentially or concurrently. The decision-maker's judgement as to the relative importance of tangible and intangible attributes, solicited through a questionnaire survey, is used as input to the proposed framework. The process starts with the treatment of intangible attributes such as financial position, volume flexibility, technological capability and supplier reputation, against qualitative criteria, using FAHP (Calabrese, Costa and Menichini 2013) and fuzzy complex proportional assessment (COPRAS-F) techniques (Zavadskas and Kaklauskas 1996), in Step 1 and Step 2 respectively. FAHP is used to establish the relative importance of the qualitative 
criteria used. COPRAS-F is used to evaluate each supplier against the quallitative criteria used in the form of scores. The resultant aggregate weighted scores are used as the coefficients of the objective function in the fuzzy linear programming (FLP) model in Step 5.

The treatment of tangible attributes such as cost, late delivery percentage and defect percentage is undertaken so that any variability associated with supplier performance is also built into relevant metrics as appropriate. Supplier production capacity is also identified at this stage and is later fed into the FLP model (Step 5) in the form of a constraint. Given that data in relation to tangible aspects are represented as fuzzy numbers in the survey dataset in Step 3, they are converted into crisp numbers using the signed distance method (see Section 3.3.1) so that they can be used in the FLP model in Step 5.
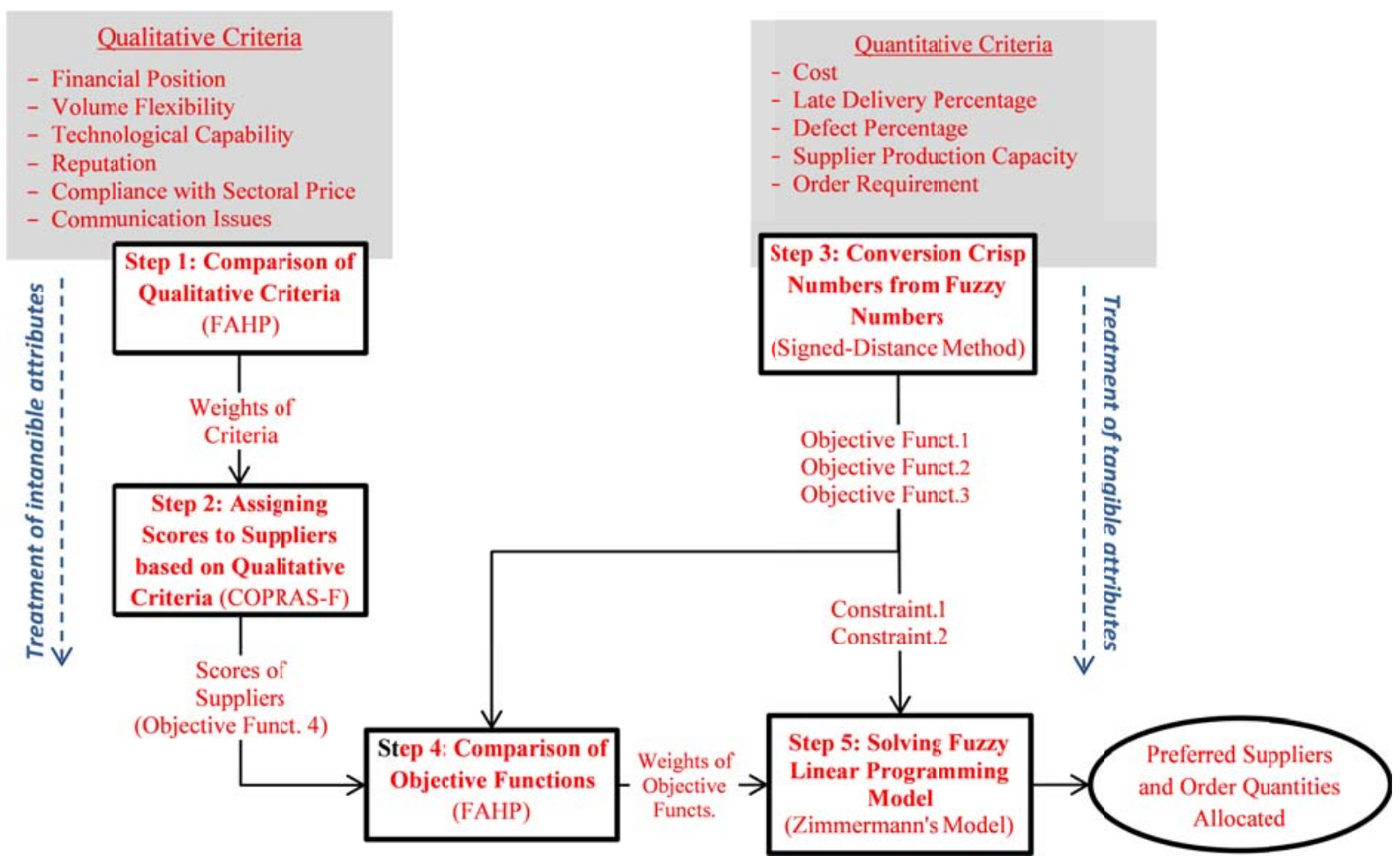

Figure 1: The Proposed Integrated Framework for Supplier Selection and Order Allocation

In Step 4 of the process, FAHP is employed for each of the tangible attributes along with the aggregated scores (derived in Step 2). The weights representing the relative importance of these attributes are used as objective function coefficients in the FLP model.

This FLP model is used to solve the problem of supplier selection and order allocation using the max-min method (see Step 5). 


\subsection{Treatment of intangible attributes}

\subsubsection{Comparison of Qualitative Criteria (Step 1) using FAHP}

The sub-steps of FAHP used in this step of the evaluation process are detailed below:

Step 1.1: The decision-makers' preferences, which are expressed in linguistic terms based on the pair-wise comparison of qualitative criteria, are first converted into triangular fuzzy numbers (TFNs) using the fuzzy weights provided in Table 1.

Table 1: Linguistic scores and fuzzy weights used for the comparison of qualitative criteria

\begin{tabular}{|c|c|}
\hline Linguistic Scores & Fuzzy \\
\hline Extremely & $(7 / 2,4,9 / 2)$ \\
\hline Very Important & $(5 / 2,3,7 / 2)$ \\
\hline Important & $(3 / 2,2,5 / 2)$ \\
\hline Moderately & $(2 / 3,1,3 / 2)$ \\
\hline Equally Important & $(1,1,1)$ \\
\hline
\end{tabular}

In order to compare qualitative criteria, these TFNs are then organised into a fuzzy decision matrix $(\tilde{B})$ as follows:

$$
\tilde{B}=\left(\tilde{b}_{i j}\right)_{n \times n}
$$

where

$$
\tilde{b}_{i j}=\left(l\left(\tilde{b}_{i j}\right), m\left(\tilde{b}_{i j}\right), u\left(\tilde{b}_{i j}\right)\right) \text { and } \tilde{b}_{i j}^{-1}=\left(\frac{1}{l\left(\tilde{b}_{i j}\right)}, \frac{1}{m\left(\tilde{b}_{i j}\right)}, \frac{1}{u\left(\tilde{b}_{i j}\right)}\right) i, j=1, \ldots n ; i \neq j
$$

and $\mathrm{l}\left(\tilde{\mathrm{b}}_{\mathrm{ij}}\right), \mathrm{m}\left(\tilde{\mathrm{b}}_{\mathrm{ij}}\right)$ and $\mathrm{u}\left(\tilde{\mathrm{b}}_{\mathrm{ij}}\right)$ represent the lower, medium and upper values of $\tilde{\mathrm{b}}_{\mathrm{ij}}$ respectively.

To assess the consistency of each pairwise comparison in $\tilde{B}$, a consistency index $(C I)$ and consistency ratio $(C R)$ are calculated following Eqns. 4 and 5, respectively (Kwong and Bai, 2003). The fuzzy decision matrix $(\tilde{B})$ is only used if the calculated $C R$ of $\tilde{B}$ is less than 0.1 . To calculate $C I, \tilde{B}$ is first converted into a crisp decision matrix $(B)$ using the centre of gravity method (Wang and Elhag, 2007):

$$
b_{i j}=\frac{l\left(\tilde{b}_{i j}\right)+m\left(\tilde{b}_{i j}\right)+u\left(\tilde{b}_{i j}\right)}{3} \quad i, j=1, \ldots n
$$

The largest eigenvalue of $B$ (i.e. $\beta_{\max }$ ) is used to evaluate $C I$ (Eqn. 4) followed by the calculation of $C R$ (Eqn. 5). 


$$
\begin{aligned}
C I & =\frac{\left(\beta_{\max }-n\right)}{n-1} \\
C R & =(C I-R I(n))
\end{aligned}
$$

The $R I(n)$, used in Eqn. 5 is a random index based on $n$ (Golden et al., 1989). Since this paper is comparing only six qualitative criteria (i.e. $n=6$ ) and four objective functions (i.e. $n=4$ ), Table 2 shows relevant $R I(n)$ for $n=6,4$.

Table 2: Random index for calculating consistency index

\begin{tabular}{|c|c|c|}
\hline$n$ & 4 & 6 \\
\hline$R I(n)$ & 0.9 & 1.24 \\
\hline
\end{tabular}

Step 1.2: Relative row sum is calculated for each row in $\widetilde{B}$ as:

$$
\widetilde{R S}_{i}=\sum_{j=1}^{n} \tilde{b}_{i j}=\left(\sum_{j=1}^{n} l\left(\tilde{b}_{i j}\right), \sum_{j=1}^{n} m\left(\tilde{b}_{i j}\right), \sum_{j=1}^{n} u\left(\tilde{b}_{i j}\right)\right) \quad i, j=1, \ldots n
$$

Step 1.3: The normalisation formula reported in Wang et al. (2008) is used to normalise relative row sums $\left(\widetilde{R S}_{i}\right)$.

$$
\begin{aligned}
\widetilde{w}_{i} & =\frac{\widetilde{R S}_{i}}{\sum_{j=1}^{n} \widetilde{R S}_{i}} \\
& =\left(\frac{\sum_{j=1}^{n} l\left(\tilde{b}_{i j}\right)}{\sum_{j=1}^{n} l\left(\tilde{b}_{i j}\right)+\sum_{q=1, q \neq j}^{n} \sum_{j=1}^{n} u\left(\tilde{b}_{q j}\right)}, \frac{\sum_{j=1}^{n} m\left(\tilde{b}_{i j}\right)}{\sum_{q=1}^{n} \sum_{j=1}^{n} m\left(\tilde{b}_{q j}\right)}, \frac{\sum_{j=1}^{n} u\left(\tilde{b}_{i j}\right)}{\sum_{j=1}^{n} u\left(\tilde{b}_{i j}\right)+\sum_{q=1, q \neq j}^{n} \sum_{j=1}^{n} l\left(\tilde{b}_{q j}\right)}\right) \\
& =\left(l\left(\widetilde{w}_{i}\right), m\left(\widetilde{w}_{i}\right), u\left(\widetilde{w}_{i}\right)\right) \quad i, j=1, \ldots n
\end{aligned}
$$

Step 1.4: TFNs for weight $\left(\widetilde{w}_{i}\right)$, i.e., $\left(l\left(\widetilde{w}_{i}\right), m\left(\widetilde{w}_{i}\right), u\left(\widetilde{w}_{i}\right)\right)$ for the $i^{\text {th }}$ criterion is converted into the crisp weight $\left(w_{i}\right)$ of the $i^{\text {th }}$ criterion by:

$$
w_{i}=\frac{l\left(\widetilde{w}_{i}\right)+m\left(\widetilde{w}_{i}\right)+u\left(\widetilde{w}_{i}\right)}{3} \quad i=1,2, \ldots . n
$$

Step 1.5: Crisp weight $\left(w_{i}\right)$ of $i^{\text {th }}$ criterion is normalised by:

$$
w_{i}^{*}=\frac{w_{i}}{\sum_{i=1}^{n} w_{i}} \quad i=1,2, \ldots . n
$$

\subsubsection{Assigning Scores to Suppliers (Step 2) using COPRAS-F}

Each supplier is then assessed against the qualitative criteria using $w_{i}^{*}$.

Step 2.1: The decision-maker's assessment of suppliers against qualitative criteria (in linguistics terms) are first converted into fuzzy scores using Table 3. These scores are then used in the fuzzy decision matrix $(\tilde{F})$ to develop utility degrees reflecting 
the aggregate scores for each supplier considering all the qualitative criteria used, as follows:

$$
\tilde{F}=\left(\tilde{f}_{s i}\right)_{t \times n} \quad i=1,2, \ldots . n \quad s=1,2, \ldots . t
$$

where:

$$
\tilde{f}_{s i}=\left(l\left(\tilde{f}_{s i}\right), m\left(\tilde{f}_{s i}\right), u\left(\tilde{f}_{s i}\right)\right) \quad i=1,2, \ldots . n \quad s=1,2, \ldots . t
$$

Table 3: Linguistic and fuzzy scores used for the evaluation of suppliers against qualitative criteria

\begin{tabular}{|c|c|}
\hline Linguistic Scores & Fuzzy Scores \\
\hline Very High & $(7,9,10)$ \\
\hline High & $(5,7,9)$ \\
\hline Medium & $(3,5,7)$ \\
\hline Low & $(1,3,5)$ \\
\hline Very Low & $(0,1,3)$ \\
\hline
\end{tabular}

Step 2.2: $l\left(\tilde{f}_{s i}\right), m\left(\tilde{f}_{s i}\right), u\left(\tilde{f}_{s i}\right)$ are fuzzy scores of the $s^{\text {th }}$ supplier with respect to the $i^{\text {th }}$ criteria and these scores are converted into crisp scores $f_{s i}$ of the $s^{\text {th }}$ supplier with respect to the $i^{\text {th }}$ criterion using:

$$
f_{s i}=\frac{l\left(\tilde{f}_{s i}\right)+m\left(\tilde{f}_{s i}\right)+u\left(\tilde{f}_{s i}\right)}{3} \quad i=1,2, \ldots . n \quad s=1,2, \ldots . t
$$

Step 2.3: After converting $l\left(\tilde{f}_{s i}\right), m\left(\tilde{f}_{s i}\right), u\left(\tilde{f}_{s i}\right)$ into crisp scores $\left(f_{s i}\right)$, a crisp decision matrix for evaluating suppliers $(F)$ is obtained. Each element of matrix $\mathrm{F}$ is normalised as:

$$
f_{s i}^{*}=\frac{f_{s i}}{\sum_{s=1}^{t} f_{s i}} \quad i=1,2, \ldots . n \quad s=1,2, \ldots . t
$$

Step 2.4: After normalisation, each element in the normalised decision matrix $\left(F^{*}\right)$ is multiplied by its corresponding normalised weights $\left(w_{i}^{*}\right)$ calculated in Step 1 to obtain the weighted normalised matrix $\left(F^{\prime}\right)$

$$
F^{\prime}=\left[f_{s i}^{\prime}\right]_{t \times n}=f_{s i}^{*} \times w_{i}^{*} \quad i=1,2, \ldots . n \quad s=1,2, \ldots . t
$$

Step 2.5: The sums of values assigned to the beneficial and non-beneficial criteria for the $s^{\text {th }}$ supplier (i.e. $K_{S}^{+}$and $K_{s}^{-}$) are derived separately from the weighted normalised matrix $F^{\prime}$. The beneficial criteria are financial position, volume flexibility, technological capability, reputation and compliance with sectoral price. The only non-beneficial criterion is communication issues. The beneficial criteria contribute 
positively toward achieving the overall goal of supplier selection and are therefore maximised. Non-beneficial criteria are minimised as they have a negative impact on the overall goal of supplier selection. Mathematically,

$$
\begin{aligned}
K_{s}^{+} & =\sum_{i=1}^{o} f_{s i}^{\prime} \\
K_{s}^{-} & =\sum_{i=o+1}^{n} f_{s i}^{\prime} \quad i=1,2, \ldots . n \quad s=1,2, \ldots . t
\end{aligned}
$$

Step 2.6: The relative importance $\left(Q_{S}\right)$ of each supplier based on qualitative criteria is calculated using the following equation:

$$
Q_{s}=K_{s}^{+}+\frac{\sum_{s=1}^{t} K_{s}^{-}}{\left(K_{s}^{-} * \sum_{s=1}^{t} \frac{1}{K_{s}^{-}}\right)} \quad s=1,2, \ldots . t
$$

Step 2.7: Finally, the utility degrees $\left(U_{S}\right)$ of each supplier, indicating the overall performance of suppliers against qualitative criteria, is evaluated as:

$$
U_{s}=\left(\frac{Q_{s}}{Q_{\max }}\right) \quad s=1,2, \ldots . t
$$

These utility degrees are used in the FLP model as the weights of the objective functions, for the purpose of maximising the total purchasing value (TPV) which also accounts for the order quantities allocated to each supplier, while considering their production capacity.

\subsection{Treatment of tangible attributes}

In this section, the evaluation of tangible attributes is illustrated using three quantitative criteria: cost, delivery and quality. The two techniques used in this part of the process are the signed distance method (Yao and $\mathrm{Wu}, 2000$; Zhou and Gong, 2004) and the max-min method (Zimmermann, 1978), the application of which is detailed below.

\subsubsection{Conversion of Fuzzy Objective Functions and Constraints (Step 3)}

This section details the conversion of the fuzzy values assigned by decision-makers in evaluating supplier performance into crisp numbers that can be incorporated into the FLP model. The fuzzy values (pessimistic, most probable and optimistic) can be derived based on historical data or expert judgements. The FLP model uses three fuzzy objective functions: minimisation of total purchase cost (TPC); minimisation of the number of units delivered late (UDL), minimisation of the number of defective units (DU) and one crisp objective function: maximisation of TPV. Equations 19-21 represent the minimisation of TPC, LDU, and DU

$$
\operatorname{Min} \tilde{Z}_{1}=\sum_{s=1}^{t} \tilde{P}_{s} \times X_{s} \quad s=1,2, \ldots . t
$$




$$
\begin{array}{cc}
\operatorname{Min} \tilde{Z}_{2}=\sum_{s=1}^{t} \tilde{L}_{s} \times X_{s} & s=1,2, \ldots . t \\
\operatorname{Min} \tilde{Z}_{3}=\sum_{s=1}^{t} \widetilde{D P}_{s} \times X_{s} & s=1,2, \ldots . t
\end{array}
$$

where, $\widetilde{P}_{S}$ is the fuzzy purchasing price, $\tilde{L}_{s}$ is the fuzzy late delivery percentage, and $\widetilde{D P}_{S}$ is the fuzzy defective percentage for the $s^{\text {th }}$ supplier; and $X_{S}$ is the order quantity for the $s^{\text {th }}$ supplier.

There is only one fuzzy constraint (supplier production capacity) in the FLP model. $\widetilde{V}_{S}$ represents the fuzzy supplier production capacity for the $s^{\text {th }}$ supplier. Mathematically,

$$
X_{s} \leq \widetilde{V}_{s} \times Y_{s} \quad s=1,2, \ldots . t
$$

These fuzzy objective functions and the only constraint are converted into crisp numbers using the signed distance method in Step 3 of the process. The signed distance method is used to convert fuzzy numbers into crisp numbers as defined in Zhou and Gong (2004). The signed distance of this fuzzy number $(\tilde{e})$ is calculated as follows:

$$
d(\tilde{e})=\frac{1}{4} \times(2 \times m(\tilde{e})+l(\tilde{e})+u(\tilde{e}))
$$

Thus, using the signed distance method, the fuzzy objective functions and constraint (Eqns. 19-22) are converted into crisp equations as:

$$
\begin{aligned}
& \operatorname{Min} Z_{1}=\sum_{s=1}^{t}\left(\frac{l\left(\tilde{P}_{S}\right)+2 \times m\left(\tilde{P}_{S}\right)+u\left(\tilde{P}_{S}\right)}{4}\right) \times X_{S} \quad s=1,2, \ldots . t \\
& \operatorname{Min} Z_{2}=\sum_{s=1}^{t}\left(\frac{l\left(\tilde{L}_{s}\right)+2 \times m\left(\tilde{L}_{s}\right)+u\left(\tilde{L}_{s}\right)}{4}\right) \times X_{S} \quad s=1,2, \ldots . t \\
& \operatorname{Min} Z_{3}=\sum_{s=1}^{t}\left(\frac{l\left(\widetilde{D P}_{S}\right)+2 \times m\left(\widetilde{D P}_{S}\right)+u\left(\widetilde{D P}_{S}\right)}{4}\right) \times X_{S} \quad s=1,2, \ldots . t \\
& X_{S} \leq\left(\frac{l\left(\widetilde{V}_{S}\right)+2 \times m\left(\widetilde{V}_{S}\right)+u\left(\widetilde{V}_{S}\right)}{4}\right) \times Y_{S} \quad s=1,2, \ldots . t
\end{aligned}
$$

The fourth objective function is maximising TPV. This objective function includes the utility degree $\left(U_{S}\right)$ of suppliers obtained in Step 2 as constants which are then used with $X_{S}$ for maximisation in FLP.

$$
\begin{gathered}
\operatorname{Max} Z_{4}=\sum_{s=1}^{t} U_{s} \times X_{s} \\
\sum_{s=1}^{t} X_{s}=O R \\
X_{s} \geq 0 \\
Y_{s}=0,1(\text { Binary }) \\
s=1,2, \ldots . t
\end{gathered}
$$

The order requirement constraint is presented in Equation 29, where $O R$ represents the total order requirement for the buyer. Equation 30 represents the non-negative constraint for the order quantity from the $s^{\text {th }}$ supplier. Equation 31 represents $Y_{s}$ as a decision variable for selecting the $s^{\text {th }}$ supplier. 
As the objective functions developed above constitute a set of linear programming models with fuzzy attributes, fuzzy linear programming (FLP) is used to select the most desirable suppliers and to allocate order quantities among those suppliers. The next subsection explains how the weights of the objective functions are derived.

\subsubsection{Comparison of objective functions (Step 4)}

There are four objective functions (developed in Step 3) and these objective functions have different priorities. FAHP is used to identify these priorities by developing weights $\left(h_{1}, h_{2}, h_{3}, h_{4}\right)$ of the four objective functions. Steps of the FAHP have been presented in Section 3.2. In this part of the methodology, the same steps are followed to develop the weights of the objective functions. The next subsection discusses the method for providing a solution in the proposed FLP model.

\subsubsection{Solving the Fuzzy Linear Programming Model (Step 5)}

The solution process of FLP starts with the determination of the maximum and minimum values of objective functions. $Z_{k}$ presents a minimising objective function and $Z_{z}$ presents a maximising objective function.

These objective functions $\left(Z_{k}, Z_{z}\right)$ can be separated into maximum $\left(Z_{k}^{+}, Z_{z}^{+}\right)$and minimum $\left(Z_{k}^{-}, Z_{z}^{-}\right)$values to solve the multi-objective problem as a single objective problem. Maximum and minimum values of the objective functions $Z_{k}, Z_{z}$ can be shown as:

$$
\begin{gathered}
Z_{k}^{-}=\operatorname{Min} Z_{k}, Z_{k}^{+}=\operatorname{Max} Z_{k} \quad k=1,2 \ldots . N \\
Z_{z}^{-}=\operatorname{Min} Z_{z}, Z_{z}^{+}=\operatorname{Max} Z_{z} \quad z=1,2 \ldots . \mathrm{G}
\end{gathered}
$$

The value of each objective $\left(Z_{k}, Z_{z}\right)$ changes linearly from $\left(Z_{k}^{-}, Z_{z}^{-}\right)$to $\left(Z_{k}^{+}, Z_{z}^{+}\right)$and the fuzzy linear membership of objective functions $\left(\mu_{k}, \mu_{z}\right)$ are shown in Figure $2 . N$ is 3 and $\mathrm{G}$ is 1 in the proposed model.
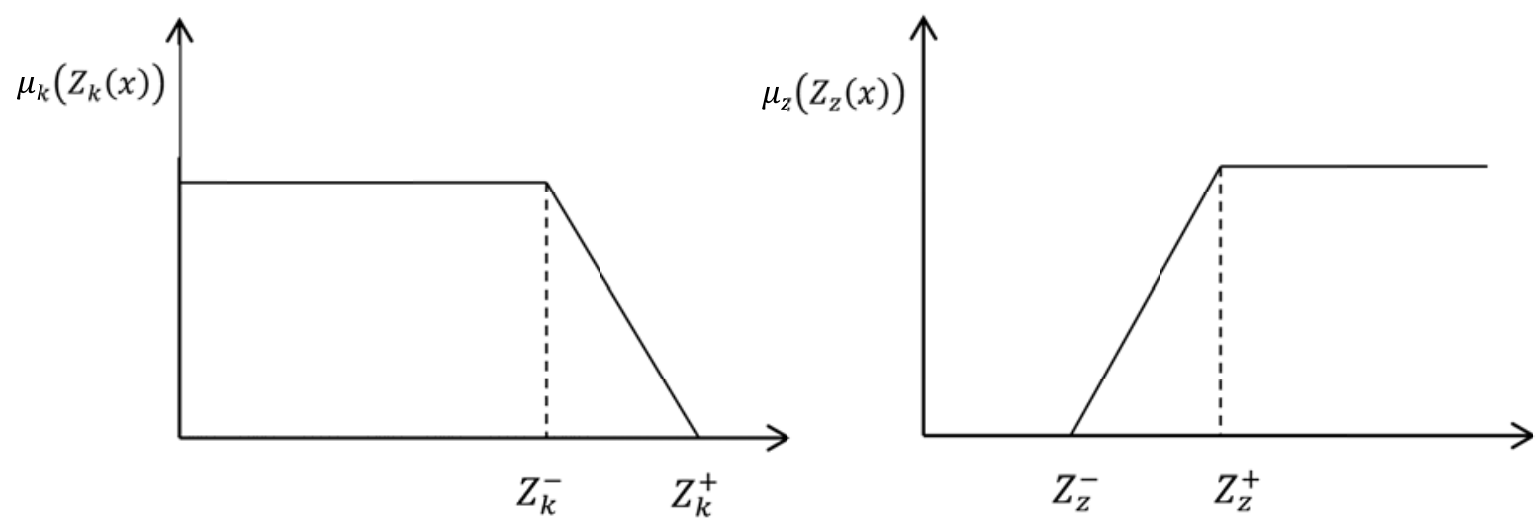

Figure 2: Fuzzy membership of objective functions 
The linear membership functions for the objective functions $\left(Z_{k}, Z_{z}\right)$ can be generalised mathematically as:

$$
\begin{gathered}
\mu_{k}\left(Z_{k}(x)\right)=\left\{\begin{array}{cc}
1, & Z_{k} \leq Z_{k}^{-} \\
\frac{\left(Z_{k}^{+}-Z_{k}(x)\right)}{\left(Z_{k}^{+}-Z_{k}^{-}\right)}, & Z_{k}^{-} \leq Z_{k} \leq Z_{k}^{+} \\
0, & Z_{k}>Z_{k}^{+}
\end{array}\right. \\
\mu_{z}\left(Z_{z}(x)\right)=\left\{\begin{array}{cc}
1, & Z_{z} \leq Z_{z}^{+} \\
\frac{\left(Z_{z}(x)-Z_{z}^{-}\right)}{\left(Z_{z}^{+}-Z_{z}^{-}\right)}, & Z_{z}^{-} \leq Z_{z} \leq Z_{z}^{+}, \quad z=1,2 \ldots . \mathrm{G} \\
0, & Z_{z} \leq Z_{z}^{-}
\end{array}\right.
\end{gathered}
$$

Maximum and minimum values of the objective functions of the proposed model can be written with respect to Eqns. 33 and 34 as:

$$
\begin{aligned}
& Z_{1}^{-}=\operatorname{Min} Z_{1}, Z_{1}^{+}=\operatorname{Max} Z_{1} \\
& Z_{2}^{-}=\operatorname{Min} Z_{2}, Z_{2}^{+}=\operatorname{Max} Z_{2} \\
& Z_{3}^{-}=\operatorname{Min} Z_{3}, Z_{3}^{+}=\operatorname{Max} Z_{3} \\
& Z_{4}^{-}=\operatorname{Min} Z_{4}, Z_{4}^{+}=\operatorname{Max} Z_{4}
\end{aligned}
$$

The linear membership function pertaining to the objective functions of the proposed model can be computed using Eqns. 35 and 36. $Z_{1}, Z_{2}$ and $Z_{3}$ are the minimising objective functions, which are similar to $Z_{k}$ and the linear membership of these objective functions are calculated using Eqn. 35. For example, the linear membership of $Z_{1}$ can be shown as:

$$
\mu_{1}\left(Z_{1}(x)\right)=\left\{\begin{array}{lr}
1, & Z_{1} \leq Z_{1}^{-} \\
\frac{\left(Z_{1}^{+}-Z_{1}(x)\right)}{\left(Z_{1}^{+}-Z_{1}^{-}\right)}, & Z_{1}^{-} \leq Z_{1} \leq Z_{1}^{+} \\
0, & Z_{1}>Z_{1}^{+}
\end{array}\right.
$$

$Z_{4}$ is a maximising objective function, which is similar to $Z_{z}$, and the linear membership of this objective function is calculated using Eqn. 36, as shown below:

$$
\mu_{4}\left(Z_{4}(x)\right)=\left\{\begin{array}{lr}
1, & Z_{4} \leq Z_{4}^{+} \\
\frac{\left(Z_{4}(x)-Z_{z}^{-}\right)}{\left(Z_{4}^{+}-Z_{4}^{-}\right)}, & Z_{4}^{-} \leq Z_{4} \leq Z_{4}^{+} \\
0, & Z_{4} \leq Z_{4}^{-}
\end{array}\right.
$$

After identifying the linear membership of objective functions, the single objective linear problem is solved in FLP. $\lambda_{k}$ and $\lambda_{z}$ represent the satisfaction degrees of objective functions $Z_{k}$ and $Z_{z}$ respectively. $\lambda_{k}$ and $\lambda_{z}$ can be expressed in terms of $\mu_{k}\left(Z_{k}(x)\right)$ and $\mu_{z}\left(Z_{z}(x)\right)$ : 


$$
\begin{aligned}
& \lambda_{k} \leq \mu_{k}\left(Z_{k}(x)\right) \\
& \lambda_{z} \leq \mu_{z}\left(Z_{z}(x)\right)
\end{aligned}
$$

The weights of the objective functions were obtained in Section 3.3.2. Therefore, the single objective function that constitutes the FLP model can be written as:

$$
\operatorname{Max}=\lambda_{1} * h_{1}+\lambda_{2} * h_{2}+\lambda_{3} * h_{3}+\lambda_{4} * h_{4}
$$

Eqns. 43 and 44 can be extended through Eqns. 34 and 35 and the FLP model is solved as a single objective linear programming problem:

$$
\begin{gathered}
\lambda_{k} \leq \frac{\left(Z_{k}^{+}-Z_{k}(x)\right)}{\left(Z_{k}^{+}-Z_{k}^{-}\right)} \\
\lambda_{z} \leq \frac{\left(Z_{z}(x)-Z_{z}^{-}\right)}{\left(Z_{z}^{+}-Z_{z}^{-}\right)} \\
\lambda_{k}, \lambda_{z} \in[0,1] \\
k=1,2 \ldots . N \\
z=1,2 \ldots . G
\end{gathered}
$$

The Eqns. 46 and 47, supplier production capacity (Eqn. 27), order requirement constraint (Eqn. 29), non-negative order requirement constraint (Eqn. 30) and binary constraint will be the constraints of the FLP model. With this step, the process of identifying the preferred suppliers and order allocation to these suppliers is concluded. In the next section, the application of the proposed model is presented to demonstrate its feasibility.

\section{EMPIRICAL VALIDATION OF THE PROPOSED FRAMEWORK}

The proposed framework was validated through its application in an apparel manufacturing company based in Turkey. To maintain anonymity the company is identified as Maxitextila. Maxitextila is one of the world's leading producers of premium woven shirts. This company has more than 30 years of experience in producing shirts for the local and international markets. Both tangible and intangible attributes identified in the previous section were evaluated against qualitative and quantitative criteria based on the data collected through a questionnaire survey administered onsite at Maxitextila. Historical quantitative data provided by the company representing year 2012 was used to evaluate supplier performance against tangible attributes. Qualitative judgements or preferences provided by four managers of Maxitextila: the Operational Director (OD), the Chief Financial Officer (CFO); the Planning Manager (PM), and the Chief Operating Officer (COO) were used to evaluate suppliers against qualitative criteria. The proposed model was applied for purchasing fabric from seven 
suppliers. The application of the proposed model is presented in Section 4.1. The comparison of results obtained by the proposed framework is presented in Section 4.2. Finally, the feasibility of the proposed model, as evaluated by the four managers, is presented in Section 4.3 .

\subsection{Application of the proposed model}

First, the treatment of qualitative attributes, including the evaluation of suppliers against qualitative criteria, based on the preferences assigned by the four managers was carried out. FAHP was used to establish the relative importance of each qualitative criterion based on the procedure described in Step 1 in Section 3.2.1. The resulting normalised weights $\left(w_{i}^{*}\right)$ of the qualitative criteria are shown in Table 4.

Table 4: The normalised weights $\left(\boldsymbol{w}_{\boldsymbol{i}}^{*}\right)$ of qualitative criteria

\begin{tabular}{|l|c|c|c|c|}
\hline \multicolumn{1}{|c|}{ Managers } & OD & CFO & COO & PM \\
\hline Financial Position & & & & \\
\hline Volume Flexibility & 0.26 & 0.16 & 0.20 & 0.31 \\
\hline Technological Capability & 0.20 & 0.19 & 0.17 & 0.20 \\
\hline Reputation & 0.14 & 0.19 & 0.15 & 0.20 \\
\hline Compliance with Sectoral Price & 0.11 & 0.16 & 0.17 & 0.13 \\
\hline Communication Issues & 0.15 & 0.14 & 0.15 & 0.07 \\
\hline CR $\leq 0.1$ & 0.14 & 0.16 & 0.16 & 0.09 \\
\hline
\end{tabular}

Based on the $w_{i}^{*}$ of the operational director in Table 4, the importance of qualitative criteria are. in order: financial position $>$ volume flexibility $>$ compliance with sectoral price $>$ technological capability $>$ communication issues $>$ reputation.

These weights $\left(w_{i}^{*}\right)$ for qualitative criteria are then used to derive supplier scores $\left(U_{s}\right)$ using COPRAS-F. The corresponding crisp scores $\left(U_{s}\right)$ for each supplier against qualitative criteria are shown in Table 5.

Table 5: Scores of suppliers $\left(\boldsymbol{U}_{\boldsymbol{S}}\right)$ under qualitative criteria

\begin{tabular}{|l|c|c|c|c|}
\hline \multicolumn{1}{|c|}{ Managers } & OD & CFO & COO & PM \\
Suppliers & & & & \\
\hline Supplier 1 & 1.0000 & 1.0000 & 1.0000 & 1.0000 \\
\hline Supplier 2 & 0.9450 & 0.9265 & 0.8933 & 0.9435 \\
\hline Supplier 3 & 0.9122 & 0.8808 & 0.8933 & 0.8999 \\
\hline Supplier 4 & 0.8067 & 0.7611 & 0.7001 & 0.8039 \\
\hline Supplier 5 & 0.9072 & 0.8719 & 0.8453 & 0.8967 \\
\hline
\end{tabular}




\begin{tabular}{|l|l|l|l|l|}
\hline Supplier 6 & 0.9588 & 0.9632 & 0.9442 & 0.9707 \\
\hline Supplier 7 & 0.8698 & 0.8262 & 0.8367 & 0.8438 \\
\hline
\end{tabular}

Fuzzy data $\left(\widetilde{P}_{S}, \widetilde{L}_{s}, \widetilde{D P}_{S}, \widetilde{V}_{S}\right)$ from the survey for 2012 are in used in fuzzy objective functions $\left(\tilde{Z}_{1}, \tilde{Z}_{2}, \tilde{Z}_{3}\right)$ and the constraint. This is converted into crisp data using the signed distance method (see Step 3). Thus, crisp objective functions $\left(Z_{1}, Z_{2}, Z_{3}, Z_{4}\right)$ and a constraint were developed followed by the computation of the weights $\left(h_{1}-h_{4}\right)$ of the objective functions using FAHP (Step 4). Linguistic values assigned by the four managers are used in identifying weights $\left(h_{1}-h_{4}\right)$ of the objective functions $\left(Z_{1}, Z_{2}, Z_{3}, Z_{4}\right)$, shown in

Table 6.

Table 6: Weights of the objective functions

\begin{tabular}{|l|c|c|c|c|}
\hline \multicolumn{1}{|c|}{ Managers } & OD & CFO & COO & PM \\
Objective Functions & & & & \\
\hline Total Cost & 0.37 & 0.39 & 0.34 & 0.34 \\
\hline Late Delivery Percentage & 0.30 & 0.29 & 0.34 & 0.38 \\
\hline Defect Percentage & 0.24 & 0.20 & 0.20 & 0.21 \\
\hline Qualitative Aspects & 0.09 & 0.12 & 0.12 & 0.07 \\
\hline CR $\leq 0.1$ & 0.061 & 0.052 & 0.055 & 0.086 \\
\hline
\end{tabular}

The crisp objective functions $Z_{1}, Z_{2}, Z_{3}, Z_{4}$ together with the supplier production capacity constraint and $\left(h_{1}-h_{4}\right)$ were then used in the FLP model to select preferred suppliers and to allocate orders (see Step 5). Even though different $\left(h_{1}-h_{4}\right)$ of $\left(Z_{1}, Z_{2}, Z_{3}, Z_{4}\right)$ were used in the FLP model, selected suppliers and allocated orders for these suppliers are the same with respect to the choices made by each manager. This confirms the internal validity of the proposed framework. The degrees of satisfaction $\left(\lambda_{1}, \lambda_{2}, \lambda_{3}, \lambda_{4}\right)$ of each objective function for each manager that was obtained from the model was 1 (the highest satisfaction value). The order quantities obtained using the proposed model and the actual quantities ordered in 2012 are provided in Table 7.

Table 7: Order Quantities $\left(\boldsymbol{X}_{\boldsymbol{s}}\right)$ from the model and Maxitextila

\begin{tabular}{|c|c|c|}
\hline Suppliers & $\begin{array}{c}\text { Real Order from } \\
\text { Maxitextila }\end{array}$ & $\begin{array}{c}\text { Order Quantities using the } \\
\text { Proposed Model }\end{array}$ \\
\hline Supplier 1 & $1,500,000$ & $1,500,000$ \\
\hline Supplier 2 & $1,000,000$ & $1,000,000$ \\
\hline Supplier 3 & $1,000,000$ & $1,000,000$ \\
\hline Supplier 4 & 600,000 & 0 \\
\hline Supplier 5 & 400,000 & 800,000 \\
\hline
\end{tabular}




\begin{tabular}{|l|l|l|}
\hline Supplier 6 & 300,000 & 300,000 \\
\hline Supplier 7 & 200,000 & 400,000 \\
\hline
\end{tabular}

As demonstrated by the results presented in Table 7, Supplier 4 is not selected by the FLP model. Purchasing order quantities from Supplier 1, Supplier 2, Supplier 3 and Supplier 6 generated using the model are the same as those actually ordered by Maxitextila. The purchasing order quantity for Supplier 5 has increased from 400,000 to 800,000 and Supplier 7's order quantity has increased from 200,000 to 400,000 . This is reflected in the order quantity formerly allocated to Supplier 4 now being shared between Supplier 5 and Supplier 7.

\subsection{Comparison of Results: proposed framework vs. Maxitextila}

The values for cost, late delivery percentage and defect percentages for order quantities obtained in Section 4.1 are compared with Maxitextila's actual order quantities for year 2012. Table 8 provides the results of this comparison. It can be seen that if Maxitextila's purchased order quantities were generated using the proposed framework, the company would have been able to save $\$ 600,000$ of the total purchasing cost of $\$ 27,200,000$ it would have received 60,000 fewer (out of 1,165,000) late delivered units and 4,000 fewer (out of 196,000) defective units.

Table 8: Savings for Maxitextila

\begin{tabular}{|c|c|c|c|}
\hline & Cost (\$) (\%) & $\begin{array}{c}\text { Late Delivery } \\
\text { (unit) (\%) }\end{array}$ & $\begin{array}{c}\text { Defective } \\
\text { (unit) (\%) }\end{array}$ \\
\hline Savings & 2.2 & 5.2 & 2.0 \\
\hline
\end{tabular}

Table 9 provides the total purchasing value (TPV) computed using the scores assigned to suppliers against qualitative criteria and the order quantities allocated for these suppliers. This TPV is represented as an objective function $\left(\mathrm{Z}_{4}\right)$ in the final FLP model, and was optimised along with other objective functions $\left(\mathrm{Z}_{1}, \mathrm{Z}_{2}, \mathrm{Z}_{3}\right)$ in allocating orders for the selected suppliers. The results show the difference in TPVs obtained using the proposed framework and the actual order quantities placed by the company in 2012.

Table 9: Total Purchase Value (TPV) of suppliers for different managers

\begin{tabular}{|l|c|c|c|c|}
\hline Managers & OD & CFO & COO & PM \\
\hline Proproach & & & & \\
\hline
\end{tabular}




\begin{tabular}{|l|l|l|l|l|}
\hline (Order quantities) & & & & \\
\hline Real order quantities (2012) & $4,665,700$ & $4,566,920$ & $4,495,380$ & $4,644,390$ \\
\hline
\end{tabular}

\subsection{Feasibility of the Proposed Framework}

An 11-point Likert scale was used to assess the feasibility of the evaluation criteria, objectives and framework used. Three numbers in the scale have linguistic definitions, which are 0 (not at all feasible), 5 (partially feasible) and 10 (completely feasible). Four questions were asked of the managers to determine the feasibility of the selection criteria, the objectives used, the suppliers selected and the results of the proposed framework. The feasibility scores assigned by the four managers are shown in Table 10 .

Table 10: Feasibility of Criteria, Objectives and the Framework

\begin{tabular}{|c|c|c|c|c|c|}
\hline Managers & OD & CFO & COO & PM & Average \\
\hline Criteria & 8 & 8 & 9 & 8 & 8.25 \\
\hline Objectives & 10 & 10 & 9 & 10 & 9.75 \\
\hline Suppliers & 9 & 9 & 8 & 8 & 8.5 \\
\hline Results & 9 & 9 & 8 & 8 & 8.5 \\
\hline
\end{tabular}

The average score for the feasibility of criteria used is 8.25 out of 10 . All the managers rated the objectives used in the proposed framework to be highly useful and completely feasible by assigning an average score of 9.75. The feasibility score for the suppliers selected using the proposed framework was 8.5, which illustrates that the same set of suppliers selected using the proposed framework, could be agreed upon by Maxitextila. The average score for the feasibility of results (TPC, LDU, and DU) was 8.5. Finally, it can be concluded that all managers rated the proposed framework and its results as extremely useful (based on the results shown in Table 10).

\section{CONCLUSIONS AND FUTURE DIRECTIONS}

This paper first highlighted the increasing significance of SES in light of recent trends pertaining to emerging supply chain practices. The paper then articulated the knowledge gaps and limitations in the current research. With a view to addressing some of these gaps and limitations, an integrated SES framework was developed by carefully selecting and combining several existing methods. This framework was empirically validated using quantitative and qualitative data drawn from a textile company based in Turkey, before evaluating its utility. The results generated through the validation and evaluation efforts 
demonstrated the efficacy of the model in terms of functionality, feasibility and relevance. Therefore, we claim that the proposed integrated SES framework has the potential to serve as a more effective alternative to existing models in terms of its capacity to help practitioners with their SES decisions.

The selection of individual methods and techniques included in the integrated model was informed by an evaluation of the 'state-of-the-art' SES techniques in terms of their complementary strengths, as well as their efficacy. The evaluation also considered the need for making the chosen techniques appealing to practitioners. The results demonstrate that this model has: the capacity to account for both tangible and intangible criteria; the capacity to deal with both qualitative and imprecise quantitative data; and the adaptability to suit varying contexts such as the different phases of the SES process and innovative combinations of tangible and intangible criteria. The results also demonstrate the model's appeal to practitioners. Overall, the proposed model is capable of addressing the limitations of existing models more comprehensively without compromising its simplicity and relevance.

We acknowledge that further testing of this model in a variety of contexts is needed in order to improve its veracity and robustness. As part of our ongoing research we are in the process of strengthening the empirical validation of this model by expanding the sample base. We are also extending the model to incorporate the stochastic dimension so that uncertainty caused by potential disruptions, including variations in demand, can also be accounted for in a more comprehensive manner.

\section{Acknowledgement}

This study has been funded by the Ministry of National Education, Republic of Turkey.

\section{REFERENCES}

Agarwal, P., Sahai, M., Mishra, V., Bag, M., Singh, V., 2011. A review of multi-criteria decision making techniques for supplier evaluation and selection. International Journal of Industrial Engineering Computations 2, 801-810.

Aissaoui, N., Haouari, M., Hassini, E., 2007. Supplier selection and order lot sizing modeling: A review. Computers \& Operations Research 34, 3516-3540.

Benyoucef, L., Ding, H., Xie, X., 2003. Supplier selection problem: selection criteria and methods. INRIA, Rapport de recherche no. 4726.

Calabrese, A., Costa, R., Menichini, T., 2013. Using Fuzzy AHP to manage Intellectual Capital assets: An application to the ICT service industry. Expert Systems with Applications 40, 3747-3755. 
Chan, F.T.S., Kumar, N., Tiwari, M.K., Lau, H.C.W., Choy, K.L., 2008. Global supplier selection: a fuzzy-AHP approach. International Journal of Production Research 46, 38253857.

Choi, T.Y., Hartley, J.L., 1996. An exploration of supplier selection practices across the supply chain. Journal of Operations Management 14, 333-343.

Dashora, Y, Kumar, S, Shukla, N, Tiwari, M.K., Improved and generalized learning strategies for dynamically fast and statistically robust evolutionary algorithms, Engineering Applications of Artificial Intelligence, Volume 21, Issue 4, June 2008, Pages 525-547.

De Boer, L., Labro, E., Morlacchi, P., 2001. A review of methods supporting supplier selection. European Journal of Purchasing \& Supply Management 7, 75-89.

De Boer, L., Van der Wegen, L.L.M., 2003. Practice and promise of formal supplier selection: a study of four empirical cases. Journal of Purchasing and Supply Management 9, 109-118.

Govindan, K., Rajendran, S., Sarkis, J., Murugesan, P., 2013. Multi criteria decision making approaches for green supplier evaluation and selection: a literature review. Journal of Cleaner Production, Available online 13 July 2013, ISSN 0959-6526, http://dx.doi.org/10.1016/j.jclepro.2013.06.046.

Igarashi, M., de Boer, L., Fet, A.M., 2013. What is required for greener supplier selection? A literature review and conceptual model development. Journal of Purchasing and Supply Management 19, 247-263.

Jain, V., Wadhwa, S., Deshmukh, S.G., 2009. Select supplier-related issues in modelling a dynamic supply chain: potential, challenges and direction for future research. International Journal of Production Research 47, 3013-3039.

Koul, S., Verma, R., 2011. Dynamic vendor selection based on fuzzy AHP. Journal of Manufacturing Technology Management 22, 963-971.

Setak, M., Sharifi, S., Alimohammadian, A., 2012. Supplier selection and order allocation models in supply chain management: a review. World Applied Sciences Journal 18, 5572 .

Shukla, N, Ceglarek, D, Tiwari, M.K., (2015) Key characteristics-based sensor distribution in multi-station assembly processes, Journal of Intelligent Manufacturing, Volume 26, Issue $1, \mathrm{pp}$ 43-58.

Shukla, N, Tiwari, MK, Shankar, R (2009) "Optimal sensor distribution for multi-station assembly process using chaos-embedded fast-simulated annealing" International Journal of Production Research, Volume 47, Issue 1, pp 187-211.

Sonmez, M., 2006. Review and critique of supplier selection process and practices, Business school paper series 2006 Loughborough University.

Viana, J.C., Alencar, L.H., 2011. An exploratory study of supplier selection and evaluation techniques, Industrial Engineering and Engineering Management (IE\&EM), 2011 IEEE 18Th International Conference on, pp. 1441-1445.

Wang, Y.-M., Elhag, T.M.S., 2007. A fuzzy group decision making approach for bridge risk assessment. Computers \& Industrial Engineering 53, 137-148.

Yao, J.-S., Wu, K., 2000. Ranking fuzzy numbers based on decomposition principle and signed distance. Fuzzy Sets and Systems 116, 275-288.

Zavadskas, E., Kaklauskas, A., 1996. Determination of an efficient contractor by using the new method of multicriteria assessment, International Symposium for "The Organization and Management of Construction”. Shaping Theory and Practice, pp. 94-104.

Zhang, D.W., Hamid, A., Bakar, A., Thoo, A.C., 2014. Sustainable Supplier Selection: An International Comparative Literature Review for Future Investigation. Applied Mechanics and Materials 525, 787-790. 
Zhou, W., Gong, P., 2004. Economic effects of environmental concerns in forest management: an analysis of the cost of achieving environmental goals. Journal of Forest Economics 10, 97-113.

Zimmermann, H.J., 1978. Fuzzy programming and linear programming with several objective functions. Fuzzy Sets and Systems 1, 45-55. 